\title{
Towards health promotion indicators
}

\section{HORST NOACK}

Department of Social and Preventive Medicine, University of Berne, Switzerland

\section{DAVID MCQUEEN}

Research Unit in Health and Behavioural Change, University of Edinburgh, United Kingdom

\section{SUMMARY}

This article examines the state of the art in health promotion indicator development over the past few years and presents five conclusions from this review. The authors put forward proposals for the development of health promotion indicators based on the question, "What research in health promotion will lead to appropriate indicators?". The authors illustrate some areas of concern both for researchers and policy- makers and suggest a number of indicators, appropriate to each of these groups, for important dimensions of health, health-related processes and health resources. The dialogue between health researchers and health decision-makers is growing and links are being made; it is important to continue this process.

\section{INTRODUCTION}

Health promotion has been defined as the process of enabling people to increase control over and to improve their health. Health promotion means action that aims at making the conditions of health more favourable through advocacy. Health promotion aims at reducing differences in health among population groups and ensuring equal opportunities and resources to enable people to realize most fully their health potential. Health promotion demands coordinated action by government and by the health, economic and social sectors, by nongovernmental and community organizations and by the media, to mediate between differing interests in society for the pursuit of health. Further, health promotion calls for concerted action and strategies to build healthy public policy; to create supportive environments; to strengthen community action directed towards health; to develop personal skills; and to reorient health services (Ottawa Charter for Health Promotion, 1986).

Although health promotion comprises familiar notions and principles, the concept as a whole is novel and highly challenging. And so is the concept of health promotion indicators. The specific request for health promotion indicators came from interested parties such as the Regional Office for Europe of the World Health Organization (WHO), largely reflecting interests principally expressed by policy-makers in government. There is not much evidence that such indicators were of primary concern to workers or researchers concerned with health promotion. The request for such indicators seems logical, for valid and reliable information can be a highly valuable tool both for bureaucratic planners and for the policy-makers and practitioners committed to advocating health promotion, enabling people to protect and improve their health, and to mediating between conflicting interests related to health.

At the start the task of identifying and developing indicators of health promotion seemed relatively straightforward. Questions were posed. What indicators exist that can be 
used now? What indicators exist that can be modified to be suitable for health promotion? What indicators need to be developed? As discussions progressed, it became obvious that not only were there no simple answers to these questions, but that there were many more questions than originally envisaged.

\section{THE STATE OF THE ART}

A review of the efforts of the past few years leads to several conclusions about the state of the art in the development of health promotion indicators.

To begin with, because research, as well as programmes, specifically directed towards health promotion hardly exists, it was just not possible to discuss health promotion indicators in any proper context. It seems that the identification and development of health promotion indicators was often seen largely as a technical issue that could be approached pragmatically simply by applying the familiar principles and methods of measurement to a new class of phenomena.

Second, the link or, rather, the interface between concepts of health and the concepts of ill health or disease have received little attention. Should good health and ill health be taken as more or less distinct phenomena caused by different conditions or factors, as the early work of Bradburn (1969) and more recent research by Heady et al. (1984) seem to suggest? This would, of course, imply distinct concepts of health promotion on the one hand and of the prevention and treatment of disease on the other, and therefore different sets of indicators. If this were the case another question would arise. Would this perspective be compatible with a holistic concept of health and a holistic concept of health promotion (Noack, 1987)?

Third, previous efforts have paid little attention to the question of who will use health promotion indicators and for what purpose. It seems that people often silently assumed that eventually a universal set of indicators would be available to fulfil all possible health information needs. Quite obviously, the kind and number of measurements needed in a research project examining, for example, the influence of social support and lifestyle factors on wellbeing would be quite different from the information selected by policy-makers or health planners to decide on a particular community health programme for adolescents. In this latter situation the public may wish to know what scientific evidence was used to make specific decisions and why.

Fourth, there does not seem to be consensus between experts on what kind of information about health promotion would be most appropriate for a particular purpose. Because the concept of health promotion largely reflects dynamic phenomena, how can we measure the process involved? There is, of course, a myriad of relevant health-related processes, such as, for example, health behaviour, patterns of social interaction, and communication. In general, these processes are difficult to categorize and to measure, and their relationship with health will frequently be debatable. One might ask whether it would be easier and more efficient to develop measures of health resources. Again, many variables could be chosen on the basis of their (frequently undefined) link with health. Why not, then, use measurements of certain dimensions of health (such as perceived wellbeing, assessed health-related quality of life, or the ability to fulfil important social roles) as indirect health promotion indicators or as outcome measures? This tends to be the approach taken in the evaluation of medical treatment and care programmes for various groups of chronically ill people (Katz, 1987; Lohr \& Ware, 1987).

Finally, because health promotion research and programmes are emerging fields of activities, yet another question has rarely been addressed. What information on health promotion is needed? It seems to be a common belief, at least among members of the health promotion community, that, in order to introduce healthy public policy and to monitor the impact of health promotion programmes, a whole new generation of quantitative indicators will be needed. This belief can be challenged. First, in most industrialized countries a vast amount of information on numerous health-related factors is routinely collected but not used because, so far, heaith has not been a major public concern. Second, it seems that most decisions in health policy and planning are based on qualitative information, including interpretations of research results and practical experience. Thus, the need for health promotion indicators must be discussed in the wider context of the health information system that a society is willing to build and maintain.

In view of these issues it seems unlikely that much additional progress will be made by 
more meetings of experts called to discuss the problems of health promotion indicators. As previous efforts suggest, the use of expert panels or Delphi techniques will yield little that is new or useful. The problem is not the generation of ever more candidates for health promotion indicators. Instead, emerging concepts and principles of health promotion, whether stemming from WHO documents such as the Ottawa Charter or other sources, need to be integrated fully into health promotion research. Until health promotion research has such a basis, it is unlikely that any set of valid and reliable indicators specific to health promotion will be forthcoming. Further, without a solid health promotion research framework, there will be no base on which to develop and test promising indicator candidates. Finally, in the saga of indicator development the cart has often been put before the horse, with the concern for providing indicators that are simple and immediately available for the so-called end users, usually policy-makers. This has led to a sense of urgency in indicator development that simply cannot be assuaged by researchers faced with limited resources and time.

\section{SOME MODEST PROPOSALS}

As indicated above, the sound development of health promotion indicators is inevitably tied to good health promotion research. The task is no longer defining appropriate health promotion indicators but determining the research in health promotion that will lead to appropriate indicators. One key element in any suggested research would be a concept of decision-linked research, as it is sometimes called. This is research linked to a dialogue with policy-makers (and/or health promotion practitioners) and to new areas for policy decisions. The major difficulty with the term is that it puts heavy emphasis on the interests and needs of the end user and tends to underplay the role and independence of the researcher. Thus we prefer a notion of integrated health policy and research, in which responsibility is shared equally between the researcher and end user. Essentially, a form of unprejudiced dialogue should take place between all interested parties; further, it should be motivated by collaboration that involves links between research and policy at three levels. Table 1 presents the framework for integrated health policy and research. It illustrates some areas of concern for both researchers and policy-makers. Researchers and policy-makers will bring issues concerning them to dialogues on health, healthrelated processes and health resources.

\section{DIA LOGUE}

\section{Dialogue on health}

Two sets of questions about levels of health can be developed: one set for researchers and a parallel set for policy-makers. Researchers may

Table 1: Framework for integrated health policy and research

\begin{tabular}{lll}
\hline Topics & Research issues & Policy issues \\
\hline Health & $\begin{array}{l}\text { Concepts and dimensions } \\
\text { of good and ill health } \\
\text { of population subgroups }\end{array}$ & $\begin{array}{l}\text { Health targets related to } \\
\text { health needs of population } \\
\text { subgroups }\end{array}$ \\
Processes & $\begin{array}{l}\text { Behaviour and actions of } \\
\text { institutions and individuals } \\
\text { accounting for positive and } \\
\text { negative health }\end{array}$ & $\begin{array}{l}\text { Commitment of organizations, } \\
\text { institutions and individuals } \\
\text { to action and behaviour }\end{array}$ \\
related to positive health \\
Resources & $\begin{array}{l}\text { Individual, organizational } \\
\text { and societal resources } \\
\text { (including knowledge, skills, } \\
\text { social networks, social } \\
\text { relations and social support) } \\
\text { accounting for positive and } \\
\text { negative health }\end{array}$ & $\begin{array}{l}\text { Maintenance and creation of } \\
\text { societal, organizational and } \\
\text { individual health resources } \\
\text { (including health information } \\
\text { systems) and reduction of } \\
\text { risks to health }\end{array}$ \\
\hline
\end{tabular}


have many questions about the meaning and nature of health; in particular, it is interesting to observe differences in these meanings in various population subgroups. For example, how are health problems and needs perceived by different groups? Policy-makers' questions may centre around the health targets for subgroups in the population. How do the targets set by the policymakers relate to needs? The overall question is whether the questions asked by both parties in the dialogue converge. The answer might well influence the type of health promotion indicators found acceptable by both groups.

For example, the researchers might see indicators that allow the description of differences among social groups with regard to wellbeing and health outlook (Ware, 1987):

- self-rating of health at present;

- personal evaluation of physical condition;

- feelings of anxiety, nervousness, tenseness, depression, moodiness, downheartedness;

- frequency and intensity of general positive affect; and

- expectations about health in the future.

Policy-makers, on the other hand, may see indicators that allow the formulation of targets for health planning and social policy (Ware, 1987):

- limitations in performance of self-care, in mobility and physical activities;

- ability to perform everyday activities;

- confinement to bed due to health problems;

- freedom of limitations in performance of usual role activities (work, housework, school work) due to poor health; and

- ratings of the intensity, duration, and frequency of pain as well as limitations in usual activities due to pain.

\section{Dialogue on health-related processes}

Many research questions centre around the general question of determining the specific individual and social processes that account for positive and negative health. For example, researchers may wish to know more about how the actions and behaviour of institutions, organizations and individuals account for changes in positive and negative health. They may be interested in:
- activities in organizational development and training of staff in order to reorient health policy towards health promotion;

- the support of public health policy by primary care physicians and specialists;

- the frequency of communications about health-enhancing behaviour between people in the workplace or students at school;

- the number of people involved in community activities related to health promotion (Consultation on Health Promotion Indicators, 1987); and

- balance between behaviour related to positive and negative health in different subgroups of the population.

Health policy-makers will probably ask about the pragmatic commitments institutions have to support these processes for positive health. They may prefer to discuss the following issues:

- the assessment of known and/or possible (positive and negative) effects of all areas of public policy (such as agriculture, transport, housing, and sports (Consultation on Health Promotion Indicators, 1987));

- the existence of interdepartmental health planning at different levels of government (Consultation on Health Promotion Indicators, 1987);

- the proportion of people in different sociodemographic groups who reduce or cease smoking or have never smoked (Consultation on Health Promotion Indicators, 1987);

- the proportion of people in different sociodemographic groups who have changed to a healthier diet;

- self-reported awareness and practice of safe sex (Consultation on Health Promotion Indicators, 1987); and

- the proportion of people who practise selfcare in the case of such minor health problems as colds, headaches, and back pain.

\section{Dialogue on health resources}

About resources, the researchers will look for the individual and societal resources (or health potentials) accounting for positive health and health-related processes. Examples of indicators that they may suggest are (Consultation on Health Promotion Indicators, 1987): 
- the existence of means of assessing the impact of public policy on health status;

- the level of knowledge of policy-makers about health issues;

- measures of inequity in income and wealth distribution;

- the existence of private and professional networks that enhance personal functioning and coping; and

- the level of public knowledge about environmental and behavioural health resources.

Policy-makers, on the other hand, will be interested in the commitments needed to improve and maintain positive health resources and to reduce health risks. They may see the following as indicators of health resources (Consultation on Health Promotion Indicators, 1987):

- the existence of consultative bodies (such as forums and councils) for and channels of communication of community health needs and demands;

- the existence of systematic programmes for the dissemination of relevant, accurate and clear information on health matters in schools;

- the existence and enforcement of traffic safety regulations, including those on the use of seat belts in cars and helmets by motorcycle riders;

- the existence and enforcement of safety regulations in the workplace; and

- the availability of networks that provide both satisfying social contact and help when needed.

\section{CONCLUSION}

The evidence accumulated from all the efforts to identify health promotion indicators shows that the dialogue between health researchers and health decision-makers is growing and that links are being made. It must be emphasized that this dialogue should continue and be fostered. Ultimately it will lead to a set of reasonable health promotion indicators. Until this process is more fully developed (which will require a couple of years), the identity of the most appropriate indicators will be unclear.

Once a consensus has been reached in this dialogue it is a relatively straightforward pro- cedure to identify available data or methods for data collection or, if data are lacking, to develop, test and apply new methods of collection. Several articles in this issue of Health promotion point out a number of powerful and readily available methods of providing useful information on health and health promotion indicators. It would be naïve, however, to think that the developing dialogue between researchers and policy-makers is free of conflict and simply a good thing. Researchers have traditions. Some of them, such as their professional independence, are compromised in such a dialogue. Policy-makers must allocate resources under pressure from vested interests. Some vested interests may clash significantly with the beliefs and values of researchers. If these conflicts can be overcome, the dialogue will lead ultimately to what may be labelled a healthy research policy.

It would be premature to end on an optimistic note at this stage in the development of a healthy research policy. Some very clear and present dangers in the current environment threaten further work. Resources for both research and policy development in many countries are diminishing, owing to both economic and political pressure. In many countries, universities and traditional research environments are under considerable pressure to reduce budgets and staff. At the same time, funding groups increasingly demand total accountability and more results with fewer resources. This allows researchers very little freedom. Other facts must also be faced: health promotion indicators will not be developed for free, and this topic must compete with others that are better developed and more coherent.

\section{REFERENCES}

Bradburn, N. M. (1969). The structure of psychological wellbeing. Chicago, Aldine.

Consultation on Health Promotion Indicators (1987). Edinburgh, Research Unit in Health and Behavioural Change, University of Edinburgh (unpublished document).

Heady, B. et al. (1984). Well-being and ill-being: different dimensions? Social indicators research, 14: 115-139.

Katz, S., ed. (1987). The Portugal Conference: measuring quality of life and functional status in clinical practice and epidemiological research. Journal of chronic diseases, 40(6).

Lohr, K. N. \& Ware, J. E., Jr., ed. (1987). Proceedings of the Advances in Health Assessment Conference. Journal of chronic diseases, 40 (Suppl. No. 1). 
Noack, H. (1987). Concepts of health and health promotion. In: Abelin, T. et al., ed. Measurement in health promotion and protection. Copenhagen, WHO Regional Office for Europe, pp. 5-28.

Ottawa Charter for Health Promotion (1986). Health promolion, 1(4): iii-v.
Ware, J. E., Jr. (1987). Standards for validating health measures: definition and content. Journal of chronic diseases, $40(6)$ : $473-480$. 